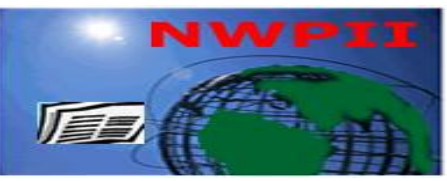

American Journal of Biomedical Sciences

ISSN: 1937-9080

nwpii.com/ajbms

\title{
Evaluation of Antioxidant Properties of Herbal Tea Powders
}

\author{
Shweta Benni ${ }^{1}$, Pramod V. Pattar ${ }^{1 *}$ and Ramalingappa ${ }^{2}$
}

\author{
${ }^{1}$ Department of Botany, Davangere University, Shivagangothri, Davangere \\ Karnataka, India. 577002. \\ *Corresponding Author \\ Dr. Pramod V. Pattar \\ Department of Botany, Davangere University, Shivagangothri \\ Davangere \\ India \\ Email:drpramodvp@gmail.com
}

${ }^{2}$ Department of Microbiology, Davangere University, Shivagangothri, Davangere

Received:18 November 2018; | Revised:24 November 2018; | Accepted: 12 December 2018

\begin{abstract}
Herbal tea is widely consumed around the world because people believed that it contained high amount of antioxidant. However, usage of different maturity of the plants as raw materials could affect the antioxidant capacities in herbal tea. These are differed in production methods and chemical composition. The most powerful antioxidant tea is green tea which is characterized by the presence of large amount of flavan3-ols known as catechins. (-) Epigallocatechins-3-gallate (EGCG) is the most abundant catechin by weight. The antioxidant activity in tea is measured by ORAP, FRAP, ABTC. Hence, the obtained results might be useful to define the formulation of these highly consumed herbal tea enhancing their health effects.
\end{abstract}

Keywords: Antioxidant property, Herbal Tea, Natural polyphenols, Phytochemicals

\section{Introduction}

Natural products and their derivatives represent more than $50 \%$ of the drugs in clinical use in the world ${ }^{[1][2]}$.

Tea, derived from Camellia sinensis L., is one of the most widely consumed beverages in the world. Te can be categorized intothree main types, depending on the level of oxidation, as green tea, oolong tea and black tea ${ }^{[3][4]}$.

Tea is second widely consumed beverage after water worldwide and because a combination factors are believed to play a role such as refreshing taste, attractive aroma and potential positive health effect $^{[5]}$.

Herbal tea has been used for health care and diseases prevention for thousands of years in many countries $^{[6]}$ because, herbal teas are convenience to take, easy to prepare, mild in action and in most cases with negligible side effects besides, cheap in price and rich in resource ${ }^{[7]}$.

The steady increase of free radicals in cells creates the conditions for so-called oxidative stress, wherein free radicals oxidize blood vessel walls, protein molecules, DNA, and lipids. These radicals are particularly active in interacting with membrane 
lipids that contain unsaturated bonds, and thus alter the properties of cell membranes. Recently a large number of diseases have been associated with oxidative stress. Oxidative stress also plays a key role in aging. The primary natural antioxidants include flavonoids, oxiaromatic acids, vitamins C and $\mathrm{E}$, carotenoids, and other compounds. In recent years bioflavonoids have become more popular since they possess anticarcinogenic, antisclerotic, antiallergenic properties, and their antioxidant activity is several tens of times greater than $\alpha$ tocopherol, vitamin $\mathrm{C}$, and $\beta$-carotene. A combination of natural bioflavonoids contained in vegetables, berries, fruits, grains, seeds, nuts, etc. is especially effective. Bioflavonoids are synthesized by plants to protect them from oxidative processes, and during long-term evolution they formed their optimal combinations. Plant-based bioflavonoids effectively protect the human body from oxidative stress; a conclusion base on substantial epidemiological evidence. Tea is one of the richest sources of antioxidants and the three major forms of antioxidant tea are green tea, oolong tea, and black tea. These teas are differed in production methods and chemical composition ${ }^{[8]}[9]$

Increasing consumption of herbal tea is a worldwide trend because people believed that supplementation of human diet with herbal provides beneficial effects to their health ${ }^{[10]}$. Herbal tea has been used for health care and diseases prevention for thousands of years in many countries ${ }^{[6]}$ Moreover, numerous epidemiological studies link herbal tea consumption to a reduction in cardiovascular diseases, cholesterol levels, diabetes, arthritis, osteoporosis and dental carries ${ }^{[11]}$.

Worldwide $80 \%$ of the tea consumed is black tea, which is also the most popular drink in Europe, North America, and North Africa (except Morocco), whereas green tea is drunk throughout Asia; oolong tea is popular in China and Taiwan (3). Approximately $76-78 \%$ of the tea produced and consumed worldwide is black tea, $20-22 \%$ is green tea, and $<2 \%$ is oolong tea ${ }^{[12][13]}$

Oxidation is an essential biological process for energy production in many living organisms. However, excessive reactive oxygen species, produced in vivo during some oxidative reactions ${ }^{[14]}$. The major antioxidants in tea are catechins, then theaflavins, thearubigins, oxyaromatic acid, flavonols, such as kawmpferol, myricetin, quercetin; flavones, such as apigenin; derivatives of Gallic acid, such as tannins, etc. The most powerful antioxidant tea is green tea which is characterized by the presence of large amount of flavan-3-ols known as catechins. (-) Epigallocatechins-3-gallate (EGCG) is most abundant catechin by weight. The antioxidant activity in tea is measured by wellknown methods, such as ORAP, FRAP, ABTC etc. Hence, the present study has been undertaken to study the presence of phytochemicals and antioxidant activity of selected herbal tea powders.

\section{Materials and Methods}

\subsection{Material}

The herbal tea powders like green tea, tea with Ashwagandha and Shatavari, tea with Amla and Vrikshamla and Daniya tea powder are purchased from the market.

\subsection{Methods}

\subsubsection{Extraction: Soxhlet extraction}

The powder samples were extracted against $\sim 350 \mathrm{ml}$ of water for $24 \mathrm{~h}$. The extract obtained was dried at room temperature and used for the further study.

\subsubsection{Free radical scavenging activity}

1.Different concentration $(10, \quad 50 \quad \& 100$ microgram) of samples in Dimethyl sulfoxide (DMSO), were taken in a series of test tubes.

2.The volume was adjusted to 500 micro litre by adding Methanol.

3.Five milliliters of a $0.1 \mathrm{mM}$ methanolic solution of 1,1-diphenyl-2-picryl hydrazyl (DPPH; from sigma-Aldrich, Bangalore) was added to these tubes and shaken vigorously.

4.A control without the test compound, but with an equivalent amount of methanol was maintained.

5.The tubes were allowed to stand at RT for 20 $\min$.

6.The absorbance of the samples was measured at $517 \mathrm{~nm}$.

7.Butylated Hydroxy Anisole (BHA) was used as reference Standard.

8.Free radical scavenging activity was calculated using the following formul; 
$\%$ Radical scavenging activity $=$

Control OD - OD X 100

Control OD

\section{Results}

The antioxidant properties of sample-01, sample-02, sample-03, and sample-04 are differing from one another (Table 1). Antioxidant properties of thirteen tropical and five temperate herbal teas were screened and comparisons were made with green, oolong and black teas of Camellia sinensis and herbal teas generally had lower antioxidant values than teas of $C$. sinensis ${ }^{[16]}$.

The using water extracts of the various teas, the total phenolic content as well as the antioxidant activities, including the reducing power, the 1,1diphenyl-2 picrylhydrazyl (DPPH) radical scavenging activity, and the inhibition of hemolysis caused by 2,2 ' -azo-bis(2-amidinopropane) dihydrochloride (AAPH)-induced lipid oxidation in erythrocyte membranes. The roasted tea contained lower levels of total phenolics than green, oolong, or black tea (green tea/oolong tea/black tea/roasted tea). The relative reducing power and DPPH scavenging activity decreased in the following order: green tea/roasted tea /oolong tea /black tea.
The samples are taken in three concentrations such as $10,50 \& 100$ micrograms. Among the test samples, sample -01 has shown significant free radical scavenging inhibition. Sample - $03 \& 04$ have moderately shown activity where as sample- 02 was found week. In 10 microgram concentration the sample-01 shows $35.49 \%$ (Fig.2, Plate-1), sample02 shows $0.96 \%$, sample- 03 and sample-04 shows $28.78 \%$ and $29.02 \%$ of antioxidant activity respectively (Table 1, Fig.1).

In 50 micrograms concentration the sample-01, sample-02 (Fig.2, Plate 1), sample-03 and sample04 shows 51.08, 6.71, 42.93 and $51.32 \%$ of antioxidant activity respectively (Table 1, Fig.1).

In 100 micrograms concentration the sample $01,02,03$ and 04 shows 58.03, 18.47, 44.12 and $44.60 \%$ of antioxidant activity respectively (Table 1 , Fig.1). From Table 1, sample-01 shows highest antioxidant activity when compared with the BHA as standard reference. The sample 03 and 04 shows moderate antioxidant activity and the sample 02 shows weak antioxidant activity (Fig.1).

The graph also shows that, among the test samples, Sample 1 has shown significant free radical scavenging inhibition. Sample 3 and 4 have moderately shown activity where as sample 2 was found week (Table 1., Fig.1) .

Table 1: Percentage of free radical scavenging activity

\begin{tabular}{|c|c|c|c|c|c|}
\hline \multirow{2}{*}{ Concentration } & \multicolumn{5}{|c|}{ \% Free radical scavenging } \\
\cline { 2 - 6 } & Sample 1 & Sample 2 & Sample 3 & Sample 4 & $\begin{array}{c}\text { Standard } \\
\text { BHA }\end{array}$ \\
\hline \multirow{2}{*}{$10 \mu \mathrm{g}$} & 35.49 & 0.96 & 28.78 & 29.02 & 23.26 \\
\hline \multirow{2}{*}{$50 \mu \mathrm{g}$} & & & & & \\
\hline & 51.08 & 6.71 & 42.93 & 51.32 & 66.43 \\
\hline $100 \mu \mathrm{g}$ & & & & & \\
\hline
\end{tabular}




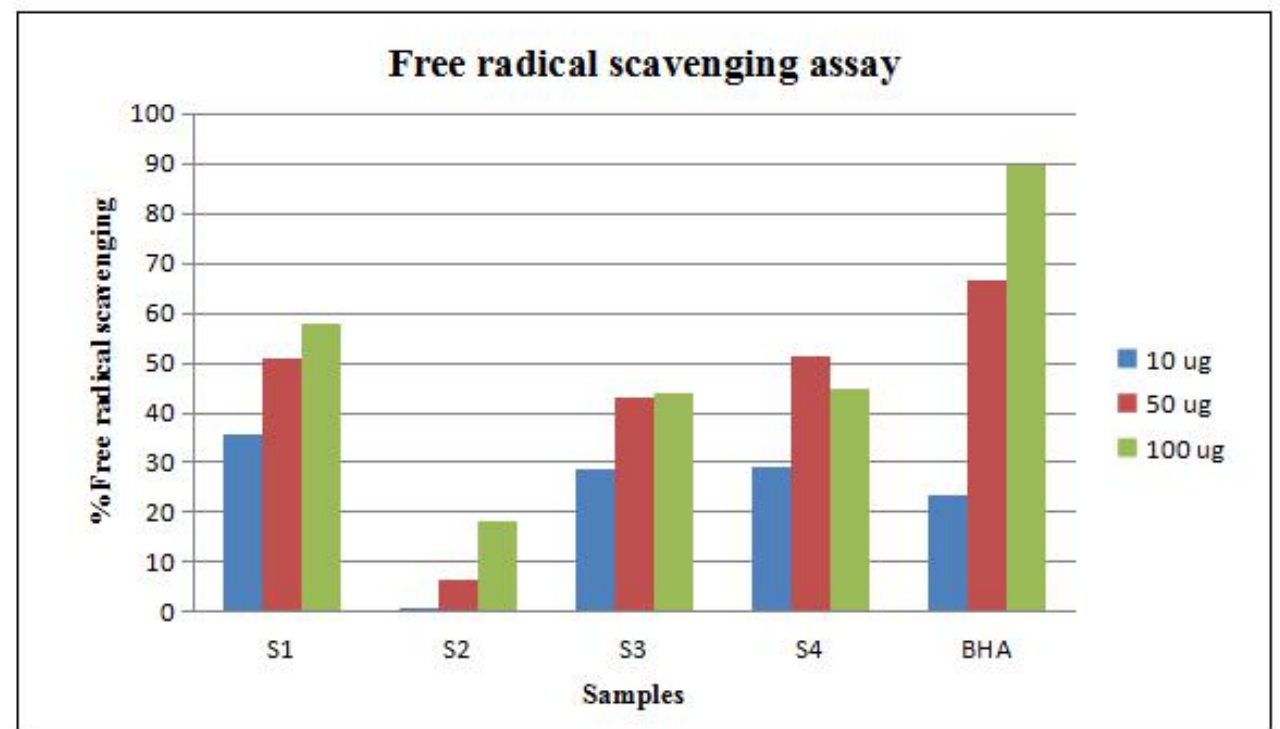

Fig. 1: Percentage of free radical scavenging activity of samples in comparison with BHA

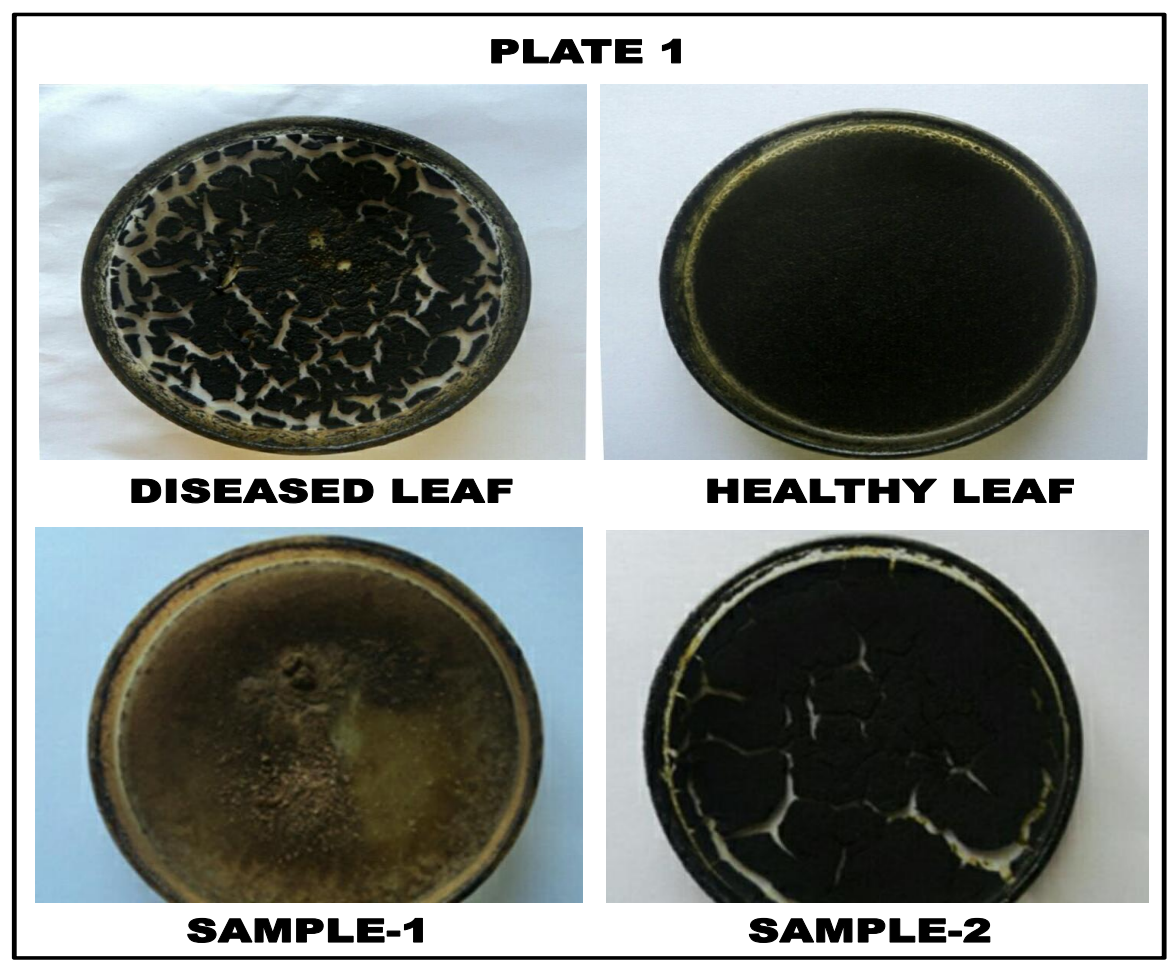

Fig.2: Plates showing extract of powder samples

\section{Discussion}

The antioxidant properties of sample-01, sample-02, sample-03, and sample-04 are differing from one another (Table 1). The tea samples are extracted with water. The antioxidant property increases with the increase in polarity of the solvent used for extraction ${ }^{[15]}$.Antioxidant properties of thirteen tropical and five temperate herbal teas were screened and comparisons were made with green, oolong and black teas of Camellia sinensis and herbal teas generally had lower antioxidant values than teas of $C$. sinensis ${ }^{[16]}$. 
The using water extracts of the various teas, the total phenolic content as well as the antioxidant activities, including the reducing power, the 1,1diphenyl-2 picrylhydrazyl (DPPH) radical scavenging activity, and the inhibition of hemolysis caused by 2,2 - azo-bis (2-amidinopropane) dihydrochloride (AAPH) - induced lipid oxidation in erythrocyte membranes. The roasted tea contained lower levels of total phenolics than green, oolong, or black tea (green tea /oolong tea /black tea /roasted tea). The relative reducing power and DPPH scavenging activity decreased in the following order: green tea /roasted tea /oolong tea /black tea. Also, green tea was more effective against AAPH-induced erythrocyte hemolysis than other teas (green tea/roasted tea/oolong tea/black tea). (Satoh et al. 2005) and same type of antioxidant property of Black tea is high in ethanol extract determined by a DPPH method ${ }^{[17]}$.

Then it is subjected to free radical scavenging assay using Butylated Hydroxy Anisole (BHA) as a reference standard ${ }^{[18]}$. The samples are taken in three concentrations such as $10,50 \& 100$ micrograms. Among the test samples, sample -01 has shown significant free radical scavenging inhibition. Sample $-03 \& 04$ have moderately shown activity where as sample-02 was found week. In 10 microgram concentration the sample-01 shows $35.49 \%$ (Fig.2.Plate-1), sample-02 shows $0.96 \%$, sample-03 and sample-04 shows $28.78 \%$ and $29.02 \%$ of antioxidant activity respectively (Table 1 , Fig.1).

The same type of resulting data showed considerable variability in both total phenols [80.5$134.9 \mathrm{mg} / \mathrm{g}$ of dry matter (DM) in black teas and $87-106.2 \mathrm{mg} / \mathrm{g}$ of DM in green teas] and catechins (5.6-47.5, 51.5-84.3, and 8.5-13.9 $\mathrm{mg} / \mathrm{g}$ of DM in black, green, and fruit teas, respectively) ${ }^{[19]}$. In 50 micrograms concentration the sample-01, sample02 (Fig.2, Plate 1), sample-03 and sample-04 shows $51.08,6.71,42.93$ and $51.32 \%$ of antioxidant activity respectively (Table 1, Fig.1).

In same way, ETAAS results showed indicated that green tea has higher content of catechins than both oolong and fermented teas (red and black) and Gallic acid content ranged from 0.039 to $6.7 \mathrm{mg} / \mathrm{g}$. [3].

In 100 micrograms concentration the sample 01,02, 03 and 04 shows 58.03, 18.47, 44.12 and
$44.60 \%$ of antioxidant activity respectively (Table 1, Fig.1). From Table 1, sample-01 shows highest antioxidant activity when compared with the BHA as standard reference. The sample 03 and 04 shows moderate antioxidant activity and the sample 02 shows weak antioxidant activity (Fig.1).

The graph also shows that, among the test samples Sample 1 has shown significant free radical scavenging inhibition. Sample 3 and 4 have moderately shown activity where as sample 2 was found week (Table 1., Fig.1). Green tea extract, a natural source of antioxidant, has been successfully used not only to enhance the flavour but also to extend the shelf-life of various food products ${ }^{[20]}$.

\section{Conclusion}

The tea has a high level of antioxidant activity. In overall antioxidant activity, tea takes a place among the highest rank, along with red wine and cocoa.

Antioxidant activity of tea is effected by many natural polyphenols: catechins, oxyaromatic acids, tannins, flavonols, thearubigins, theaflavins, etc. Antioxidant activity of various tea grades, as identified by modern methods, descends in the following order: of green tea is effected mainly by catechins $(90 \%)$, of black tea by theaflavins and thearubigins. Rapid determination of the total antioxidant content in tea by an amperometric method can be used to assess tea quality and authenticity.

\section{Acknowledgement}

Authors acknowledge the Co-ordinator, Department of Botany, Davangere University, Davangere for the facilities extended.

\section{References}

1 Cowan MM. Plant products as antimicrobial agents. Clin Microbiol Rev 1999; 12(4): 564582 [PMID: 10515903 PMCID: PMC88925]

2 Sofowora , E.A.; Medicinal Plants and Traditional Medicine in Africa. London: Willey, 1984.

3 Chan EW, Soh EY, Tie PP, Law YP. Antioxidant and antibacterial properties of 
green, black, and herbal teas of Camellia sinensis. Pharmacognosy Res 2011; 3(4): 266272 DOI: $10.4103 / 0974-8490.89748$

4 Babu PV, Liu D. Green tea catechins and cardiovascular health: an update. Curr Med Chem 2008; 15(18): 1840-1850

5 Sari, F.;Velioglu, Y. S. Effects of particle size, sample on time and temperature, and derivatization time on determination of theanine in tea. Journal of Food Composition and Analysis, 2011, 24 (8), 1130 - 1135.

6 Zhao J, Deng JW, Chen YW, Li SP. Advanced phytochemical analysis of herbal tea in China. J Chromatogr $\boldsymbol{A}$ 2013; 1313: 2-23 DOI: 10.1016/j.chroma.2013.07.039

7 Tschiggerl, C.; Bucar, F. The volatile fraction of herbal teas, Phytochemistry Reviews, 2012, 11 (2-3), 245-254.

8 Balentine DA, Wiseman SA, Bouwens LC. The chemistry of tea flavonoids. Crit Rev Food Sci Nutr 1997; 37(8): 693-704 DOI: $\underline{10.1080 / 10408399709527797}$

9 Lambert JD, Elias RJ. The antioxidant and prooxidant activities of green tea polyphenols: a role in cancer prevention. Arch Biochem Biophys 2010; 501(1): 65-72 DOI: 10.1016/j.abb.2010.06.013

10 Quispe C, Viveros-Valdez E, SchmedaHirschmann G. Phenolic constituents of the Chilean herbal tea Fabiana imbricata R. et P. Plant Foods Hum Nutr 2012; 67(3): 242-246 DOI: $10.1007 / \mathrm{s} 11130-012-0302-4$

11 Horžić, D.; Komes, D.; Belščak, A.; Ganić, K. K.; Iveković, D.; Karlović, D. The composition of polyphenols and methylxanthines in teas and herbal infusions, Food Chemistry, 2009, 115(2), 441 - 448.

12 Costa LM, Gouveia ST, Nobrega JA. Comparison of heating extraction procedures for $\mathrm{Al}, \mathrm{Ca}, \mathrm{Mg}$, and $\mathrm{Mn}$ in tea samples. Anal Sci 2002; 18(3): 313-318
13 Zuo Y, Chen H, Deng Y. Simultaneous determination of catechins, caffeine and gallic acids in green, Oolong, black and pu-erh teas using HPLC with a photodiode array detector. Talanta 2002; 57(2): 307-316 14 Blokhina O, Virolainen E, Fagerstedt KV. Antioxidants, oxidative damage and oxygen deprivation stress: a review. Ann Bot 2003; 91 Spec No: 179-194

15 Nishimura, M.; Satoh, E.; Tohyama N. Comparison between the antioxidant activity of toasted tea and that of green, oolong, and black tea, International Journal of Food Sciences and Nutrition, 2005, 56(8), 551-559.

16 Chan, E.W.C.; Lim, Y.Y.; Chong, K.L.; Tan, J.B.I.; Wong, S.K. Antioxidant properties of tropical and temperate herbal teas, Journal of Food Composition and Analysis, 2010, 23 (2), 185-189.

17 Satoh E, Tohyama N, Nishimura M. Comparison of the antioxidant activity of roasted tea with green, oolong, and black teas. Int J Food Sci Nutr 2005; 56(8): 551-559 DOI: $\underline{10.1080 / 09637480500398835}$

18 Venselow, P.; Babu, A.; Liu, D. Effect of antioxidants in disease treatment, Journal of International food research. 2012, 46, 64-72.

19 Cao, M.N.; Cabrera, C.; Artacho, R. Determination of chemistry, antioxidant properties and food application of black tea, Journal of Nutrition, 2016, 68, 201-215.

20 Khokhar S, Magnusdottir SG. Total phenol, catechin, and caffeine contents of teas commonly consumed in the United kingdom. $\boldsymbol{J}$ Agric Food Chem 2002; 50(3): 565-570

21 Nuengchamnog and Senanayake ; Determination of antioxidant activity of herbal tea powder, Journal of Science of Total Environment, 2009, 27, 467-498. 